\title{
LA EXTENSIÓN UNIVERSITARIA: ANÁLISIS DE SU ORGANIZACIÓN Y GESTIÓN EN FACULTADES DE LA UNIVERSIDAD NACIONAL DE ASUNCIÓN
}

UNIVERSITY EXTENSION: ANALYSIS OF ITS ORGANIZATION AND MANAGEMENT in faculties of the National University of Asunción

Lic. María Luisa Torres de Ruiz

\section{RESUMEN}

Este estudio analiza la organización y la gestión de la extensión universitaria en siete facultades de la Universidad Nacional de Asunción (UNA): Facultad de Ciencias Exactas y Naturales, Facultad de Odontología, Facultad de Filosofía, Facultad de Ciencias Veterinarias, Facultad de Ciencias Agrarias, Facultad Politécnica y Facultad de Arquitectura Diseño y Arte. El trabajo de campo se desarrolló entre los meses de mayo y octubre de 2011. Para esta investigación se realizó un estudio de tipo descriptivo, de diseño no experimental, y se adoptó el enfoque mixto: cuali-cuantitativo. Las técnicas e instrumentos utilizados para la recolección de datos fueron la encuesta, con un cuestionario abierto y otro cerrado, y la entrevista, aplicadas a directivos, docentes y estudiantes de las facultades en estudio, y el análisis de documentos oficiales de las mismas. Los resultados revelan que las siete facultades de la UNA poseen en su estructura órganos de gestión encargados de la extensión universitaria, así como una organización y gestión establecidas en sus organigramas y en los documentos normativos de la misma universidad y de cada facultad.

Palabras clave: Extensión universitaria, estructura organizacional, gestión, órganos de gestión. 


\section{ABSTRACT}

This study analyzes organization and management of the university extension in seven faculties of the National University of Asunción (UNA) these are the Faculties of: Exact and Natural Sciences, Odontology, Philosophy, Veterinarian Sciences, Agricultural Sciences, the Faculty specialized in technical subjects and the Architecture, Design and Art Faculty. This work was developed between May and October 2011. For this investigation a descriptive study was made with a non-experimental design, and it was focused according to quantity and quality. In order to receive the information the techniques and instruments used were the survey, with an open questionnaire and another in closed format, and the interview, which was applied to managers, teachers and students in these studied faculties, and also their legal documents analysis was carried out. The results show that in all these seven faculties of the UNA is found a structure of organizations in charge of the university extension and also there is organization and management established in the organization charts and regulation documents of each faculty and in the university as well.

Keyrords: university extension, structure of organizations, management, management organizations. 


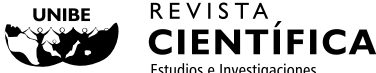

\section{INTRODUCCIÓN}

En un tiempo de grandes desafíos para la educación superior, por las necesidades de cambio de paradigmas en las diferentes dimensiones que comprende este nivel educativo, de modo a responder a los desafíos del siglo XXI, y por los procesos necesarios de evaluar la calidad de sus servicios, surge la "Extensión universitaria: su Ooganización y gestión" como un tema relevante para el análisis y la discusión entre los actores educativos de este nivel.

La extensión en sus múltiples conceptualizaciones es nombrada como uno de los fines en el que se sustenta la misión de las universidades; y como su función principal, el servicio a la sociedad.

La importancia de este tema en la educación superior se hace evidente en tanto ha sido tratado en diversos foros, conferencias y cumbres mundiales y regionales. Así, la Conferencia Mundial de Educación Superior, realizada en París en el año 1998, por iniciativa de la UNESCO, reforzó la función de servicio a la sociedad de la educación superior y en el documento declarativo que produjo la citada conferencia se reafirma el compromiso de concretar las actividades encaminadas a erradicar la pobreza, la intolerancia, la violencia, el analfabetismo, el hambre, el deterioro del medio ambiente y las enfermedades (La Educación Superior en el Siglo XXI. Visión y acción. Conferencia Mundial sobre la Educación Superior. UNESCO, 1998).

Desde estas declaraciones se deduce la importancia de analizar la extensión en las universidades, considerando que a través de ella los actores educativos fomentan su vocación de servicio, desarrollan una conciencia de responsabilidad social y tienen la oportunidad de conocer la realidad de la sociedad para transformarla.

La elección del tema responde al interés de averiguar si la extensión, como una de las tres funciones de la universidad, es considerada dentro del proyecto educativo de las instituciones universitarias en el mismo nivel que la docencia, por lo cual se ha buscado analizar la estructura organizativa, la gestión, los propósitos y las acciones de la extensión en las unidades académicas de la mayor universidad de gestión pública y la de mayor trayectoria (123 años de funcionamiento) en nuestro país.

Dado que el presente trabajo pretende caracterizar la estructura de organización y gestión de la extensión, es importante definir los términos; así, el Diccionario de la Real Academia Española (2001) 
define la estructura como una distribución de las partes de una cosa; por consiguiente, la estructura organizacional de una institución trata de la distribución intencional de áreas, roles, funciones, etc.

De aquí se deduce que, para poder afirmar que en las facultades en estudio existe una estructura organizacional de la extensión universitaria, se la debe visualizar en un organigrama y encontrarla establecida en los documentos que respaldan sus políticas.

Respecto a la gestión, Martín-Moreno Cerrillo (2006) expresa que hay que recordar que es una de las funciones del ejercicio de la dirección y la administración de una empresa. Por consiguiente, al hablar de órgano de gestión en la extensión universitaria, se concreta la idea de una estructura que se organiza y entra en funcionamiento a través de sus directivos y demás actores.

Desde su instalación en las universidades, la extensión universitaria ha estado marcada en su desarrollo por una diversidad de enfoques y modelos empleados para su concreción en actividades también muy variadas y con propósitos diferentes.

Esta realidad ha tenido como consecuencia que incluso al interior de la misma universidad, en las unidades académicas se vayan asumiendo perspectivas variadas respecto de la extensión universitaria y que se desarrollen diversos tipos de actividades como parte de esta función de la educación superior.

La característica mencionada llevó a formular las siguientes preguntas:

- ¿Cuál es la estructura de organización de la extensión en las facultades de la Universidad Nacional de Asunción?

- ¿Cómo se gestionan las acciones o programas de extensión universitaria en las facultades de la UNA?

- ¿Qué propósitos tienen las acciones de extensión universitaria en las facultades de la UNA?

- ¿Cuáles son las acciones de extensión universitaria que desarrollan las facultades de la UNA?

- ¿Cómo se sistematizan las acciones de extensión universitaria que se realizan en las facultades de la UNA?

Todas estas cuestiones se sintetizaron en este problema central:

- ¿Cómo se organiza y gestiona la extensión universitaria en las unidades académicas de la Universidad Nacional de Asunción? 
Para responder a las preguntas, se planteó como Objetivo General:

- Analizar la organización y la gestión de la extensión universitaria en siete facultades de la Universidad Nacional de Asunción.

\section{Y como objetivos específicos:}

1. Describir la estructura organizativa de la extensión en las facultades de la UNA.

2. Identificar las características de la gestión de acciones de extensión universitaria en las facultades de la UNA.

3. Reconocer los propósitos que tiene la extensión en las facultades de la UNA.

4. Clasificar las acciones de extensión universitaria que desarrollan las facultades de la UNA.

5. Identificar los documentos que sistematizan las acciones de extensión universitaria realizadas por las facultades de la UNA estudiadas.

Motivos suficientes para llevar a cabo este trabajo fueron también: lograr mayores conocimientos teóricos acerca de las implicancias de la extensión universitaria como función o eje de acción de las universidades, demostrar la importancia de la extensión para una gestión de calidad en las universidades, contar con elementos que pudieran contribuir a proponer políticas y estrategias operativas para la ejecución de proyectos de extensión universitaria.

Con relación a la relevancia social, el aporte de esta investigación radica en presentar a la sociedad académica las prácticas de extensión de una universidad del país a fin de plantear alternativas orientadas a fortalecer la organización y funcionamiento de este eje de acción relevante, considerando que forma parte del proyecto académico de las carreras y por consiguiente son objeto de evaluación en los procesos de acreditación.

\section{METODOLOGÍA}

Para este trabajo de investigación que se propuso analizar la organización y gestión de la extensión en facultades de la Universidad Nacional de Asunción, se optó por un diseño no experimental y un estudio de tipo descriptivo. La investigación no tuvo intención de generalizar los resultados por la característica del estudio planteado. 
En cuanto al lugar y época de la investigación, el estudio se realizó en siete facultades de la Universidad Nacional de Asunción. Dos ubicadas en la ciudad de Asunción y cinco en la ciudad universitaria de San Lorenzo. El trabajo de campo se llevó a cabo entre los meses de mayo y octubre de 2011.

La elección de la UNA para la realización de la investigación respondió al hecho de que se trata de la institución con mayor cantidad de carreras, unidades académicas, estudiantes y profesores, al mismo tiempo de ser la más antigua y por lo tanto con más trayectoria en el Paraguay. Por otro lado, se consideró el hecho de que posee una estructura formalizada para el desarrollo de la extensión universitaria.

Hablar de estructura organizacional en una institución implica haber pasado por un proceso de construcción de áreas o estamentos dentro de la misma. Es por eso que se presenta en el siguiente cuadro las unidades académicas estudiadas con datos que dan cuenta del proceso organizacional vivido.

Tabla 1- Facultades de la UNA en estudio

\begin{tabular}{|c|c|c|}
\hline Facultades & Año de creación & Acreditación \\
\hline Facultad de Odontología & 1937 & En proceso \\
\hline Facultad de Filosofía & 1948 & En proceso \\
\hline $\begin{array}{l}\text { Facultad de Ciencias } \\
\text { Veterinarias }\end{array}$ & $\begin{array}{c}1954 \text { como Facultad de } \\
\text { Agronomía y Veterinaria. } \\
1974 \text { Facultad de Ciencias } \\
\text { Veterinarias. }\end{array}$ & $\begin{array}{l}\text { ARCUSUR y Modelo } \\
\text { Nacional de Paraguay }\end{array}$ \\
\hline $\begin{array}{l}\text { Facultad de Ciencias } \\
\text { Agrarias }\end{array}$ & $\begin{array}{c}1954 \text { como Facultad de } \\
\text { Agronomía y Veterinaria. } \\
1974 \text { Facultad de Ingeniería } \\
\text { Agronómica. } \\
1994 \text { recibe el nombre de } \\
\text { Facultad de Ciencias Agrarias. }\end{array}$ & $\begin{array}{l}\text { ARCUSUR y Modelo } \\
\text { Nacional de Paraguay }\end{array}$ \\
\hline $\begin{array}{l}\text { Facultad de Arquitectura, } \\
\text { Diseño y Arte }\end{array}$ & 1954 & $\begin{array}{l}\text { ARCUSUR y Modelo } \\
\text { Nacional de Paraguay }\end{array}$ \\
\hline Facultad Politécnica & 1979 & En proceso \\
\hline $\begin{array}{l}\text { Facultad de Ciencias Exactas y } \\
\text { Naturales }\end{array}$ & 1986 & En proceso \\
\hline
\end{tabular}

Fuente: Elaboración de la autora con base en datos bibliográficos, 2012. 
El enfoque adoptado fue el mixto: cuali-cuantitativo debido a que el tema a ser estudiado presenta variables que por un lado permitieron recoger datos cuantificables a través de cuestionarios cerrados y por otra, se debió acudir a entrevistas con guías de preguntas abiertas.

La población estudiada estuvo constituida por las doce facultades con las que cuenta la Universidad Nacional de Asunción.

Para la realización de la presente investigación se seleccionaron como muestra siete unidades académicas de la Universidad Nacional de Asunción; por consiguiente, las unidades de análisis fueron las facultades. Se menciona que la mayoría de las facultades tiene más de una carrera, entre las cuales algunas ya fueron acreditadas.

Como sujetos participantes se nombra, en primer lugar, a los directores y coordinadores de los departamentos de Extensión Universitaria, por ser parte principal de la estructura organizacional de dichas instancias. Se menciona que de las siete facultades estudiadas, cinco cuentan con directores, una con un jefe de departamento y una con un coordinador de Extensión Universitaria.

Los docentes y estudiantes, también se constituyeron en sujetos participantes y fueron seleccionados de modo intencional. Los docentes, por serlos responsables directos de la coordinación y el seguimiento de la ejecución de la extensión, y los estudiantes por ser los actores que concretan la extensión universitaria por medio de las actividades.

Para la recolección de los datos, se aplicaron las siguientes técnicas e instrumentos:

1. Las encuestas a directivos y estudiantes, con un cuestionario de preguntas cerradas y a docentes con un cuestionario de preguntas abiertas. El cuestionario se organizó en dos grandes bloques, uno intentando recoger datos de identificación y el otro, con un total de diecisiete preguntas que corresponden a la organización, gestión, propósitos y acciones de la extensión universitaria.

2. La entrevista aplicada a cada directivo de la extensión, de las siete facultades. Estas entrevistas se realizaron con el objetivo de ampliar y enriquecer las informaciones obtenidas por medio del cuestionario cerrado. Las entrevistas estaban basadas en las preguntas del cuestionario, pero ampliándose la conversación a base del interés de responder que tenía cada directivo. 
3. El análisis documental: se aplicó sobre el Estatuto de la UNA, el Reglamento General de Extensión Universitaria de la UNA, Reglamentos de Extensión de las facultades en estudio, revistas de extensión universitaria de la UNA. El análisis de contenido fue realizado considerando todas las variables del estudio y sus respectivos indicadores.

Para una mejor organización de los datos colectados y su posterior análisis, se elaboró una matriz de variables e indicadores.

Tabla 2 - Matriz de variables e indicadores

\begin{tabular}{|c|c|c|}
\hline Variables & $\begin{array}{l}\text { Definición } \\
\text { conceptual }\end{array}$ & Indicadores \\
\hline $\begin{array}{l}\text { Estructura } \\
\text { organizativa }\end{array}$ & $\begin{array}{l}\text { Ubicación que ocupa la } \\
\text { extensión dentro de la } \\
\text { estructura organizacional } \\
\text { y aspectos políticos } \\
\text { normativos relacionados } \\
\text { con la misma. }\end{array}$ & $\begin{array}{l}\text { Política existente } \\
\text { Ubicación de la extensión universitaria en } \\
\text { el organigrama. } \\
\text { Órganos responsables de la gestión. }\end{array}$ \\
\hline Gestión & $\begin{array}{l}\text { Proceso que involucra } \\
\text { la planificación, } \\
\text { ejecución, seguimiento } \\
\text { y evaluación de la } \\
\text { extensión, así como } \\
\text { la definición de los } \\
\text { participantes y los } \\
\text { recursos necesarios. }\end{array}$ & $\begin{array}{l}\text { Diseño } \\
\text { Participantes de la ejecución } \\
\text { Seguimiento } \\
\text { Evaluación } \\
\text { Normativas que regulan las acciones. } \\
\text { Documentos de registro de las actividades. } \\
\text { Financiamiento } \\
\text { Recursos disponibles. }\end{array}$ \\
\hline Propósitos & $\begin{array}{l}\text { Se define como } \\
\text { la finalidad de las } \\
\text { acciones de extensión } \\
\text { universitaria. }\end{array}$ & $\begin{array}{l}\text { Funciones } \\
\text { Objetivos } \\
\text { Implicancias dentro y fuera de la } \\
\text { universidad }\end{array}$ \\
\hline Acciones & $\begin{array}{l}\text { Se refieren a las } \\
\text { actividades desarrolladas } \\
\text { en el marco de la } \\
\text { extensión. }\end{array}$ & $\begin{array}{l}\text { Tipo de actividades } \\
\text { Lugar de realización } \\
\text { Participantes } \\
\text { Beneficiarios }\end{array}$ \\
\hline
\end{tabular}

Fuente: Elaboración de la autora, 2011. 
El análisis de documentos se realizó conforme a la disponibilidad de los documentos, siguiendo las variables e indicadores del estudio. Esos documentos fueron: el Estatuto de la UNA, el Reglamento General de Extensión Universitaria de la UNA, los reglamentos internos de extensión de la mayoría de las facultades en estudio y las revistas $\mathrm{N}^{\circ} 2,3$ y 4 de Extensión Universitaria de la UNA.

\section{RESULTADOS}

Se presentan a continuación los resultados obtenidos considerando las variables investigadas, integrando en cada una de ellas los datos cuantitativos y cualitativos recogidos durante el trabajo de campo con los actores participantes.

\section{VARIABLE 1: ESTRUCTURA ORGANIZACIONAL DE LA EXTENSIÓN UNIVERSITARIA}

\section{Ubicación de la extensión}

Tabla 3 -Extensión universitaria en la estructura organizacional

\begin{tabular}{|c|l|l|l|}
\hline FACULTAD & Dirección & Departamento & Coordinación \\
\hline Odontología & & & \\
\hline Filosofía & & & \\
\hline C. Veterinarias & & & \\
\hline $\begin{array}{c}\text { C. Agrarias } \\
\text { Arquitectura, Diseño y } \\
\text { Arte }\end{array}$ & & & \\
\hline $\begin{array}{c}\text { Politécnica } \\
\text { Ciencias Exactas y } \\
\text { Naturales }\end{array}$ & & & \\
\hline
\end{tabular}

Fuente: Datos de la entrevista aplicada a directivos, 2011.

En las entrevistas, los directivos mencionaron la organización de la extensión en sus facultades, describiendo del siguiente modo:

"En la Facultad de Odontología la instancia se denomina Dirección de Extensión y Cultura; fue creada como tal hace 16 años, desarrollando a 
partir de allí actividades en forma sistemática. Acompañan también esta dirección dos docentes investigadoras".

Respecto de la organización, otro agregó:

"Dentro de cada carrera de la Facultad de Ciencias Agrarias se encuentran los departamentos que tienen sus coordinadores de Extensión y la Dirección de Extensión depende del Decanato".

De acuerdo con el análisis aplicado al Reglamento Interno de Extensión de esta facultad, se constata que la Dirección de Extensión Universitaria fue creada en el año 2007.

Similar organización a las dos anteriormente descriptas es la que sigue:

"En la FACEN la Dirección tiene 5 años, pero 20 años como Coordinación. Hay una Dirección de Extensión General para la Facultad y coordinaciones de Extensión por Carrera".

Un dato resaltante y diferenciador constituye el manifestado por el entrevistado de la Facultad Politécnica:

“...el órgano se denomina Dirección de Investigación, Posgrado y Extensión; cuenta con un director y un coordinador de Extensión. Cada carrera tiene un profesor-orientador de Extensión Universitaria. Son 17 personas en esta dirección".

El responsable de la extensión en la institución, que la organizan como departamento, expresó que en el “...año 2007 se crea el Departamento de Extensión de la Facultad de Ciencias Veterinarias", lo que implica una instancia de reciente creación.

\section{Política de EXTensión}

Respecto de la existencia de políticas de extensión declaradas en algún documento institucional, en el cuadro pueden observarse los resultados. 
Tabla 4 - Documentos en que se expresan políticas de extensión

\begin{tabular}{|l|l|l|l|l|l|}
\hline \multicolumn{1}{|c|}{ Facultad } & Estatuto & $\begin{array}{c}\text { Reglamento } \\
\text { General de } \\
\text { Extensión }\end{array}$ & $\begin{array}{c}\text { Reglamento } \\
\text { Interno de } \\
\text { Extensión }\end{array}$ & $\begin{array}{c}\text { Planificación } \\
\text { institucional } \\
\text { anual }\end{array}$ & $\begin{array}{c}\text { Manual de } \\
\text { Operaciones }\end{array}$ \\
\hline Odontología & & & & & \\
\hline Filosofía & & & & & \\
\hline $\begin{array}{l}\text { Ciencias } \\
\text { Veterinarias }\end{array}$ & & & & & \\
\hline Ciencias Agrarias & & & & & \\
\hline $\begin{array}{l}\text { Arquitectura, } \\
\text { Diseño y Arte }\end{array}$ & & & & & \\
\hline Politécnica & & & & & \\
\hline $\begin{array}{l}\text { Ciencias Exactas } \\
\text { y Naturales }\end{array}$ & & & & & \\
\hline
\end{tabular}

Fuente: Datos de la entrevista aplicada a directivos, 2011.

Respecto de las líneas de acción o políticas de extensión en la entrevista con los directivos, se rescataron las siguientes expresiones:

"En el Reglamento de Extensión de Ciencias Agrarias se establecen las funciones y los créditos obligatorios a lograr al cierre de cada carrera, que son tres (3) créditos por 45 horas de extensión”.

Otro documento que revela la concreción de las políticas de extensión, constituye la Planificación Institucional Anual. Al respecto, expresaron algunos directivos:

"En la FOUNA presentamos la planificación en diciembre del año anterior a la ejecución y debe ser aprobada por el Consejo Directivo de la Facultad".

Otro directivo expresó:

"El Plan Estratégico de la Politécnica se desprende del Plan Estratégico de la UNA".

Con respecto a la articulación de las políticas de cada facultad y la del Rectorado, en la entrevista realizada, el director general de Extensión manifestó lo siguiente: "A través de la Dirección General de Extensión se articulan las políticas de extensión universitaria en todas las 
facultades de la UNA. En este momento se encuentra instalada una Red de Extensión Universitaria, bien articulada".

\section{Órganos De GESTIÓN}

Los resultados de los datos colectados en la encuesta a docentes acerca del lugar que ocupa la extensión universitaria en el organigrama de las facultades donde ejercen la docencia, se presentan en el siguiente gráfico.

\section{Gráfico 1 - Órganos de gestión de la extensión universitaria según docentes}

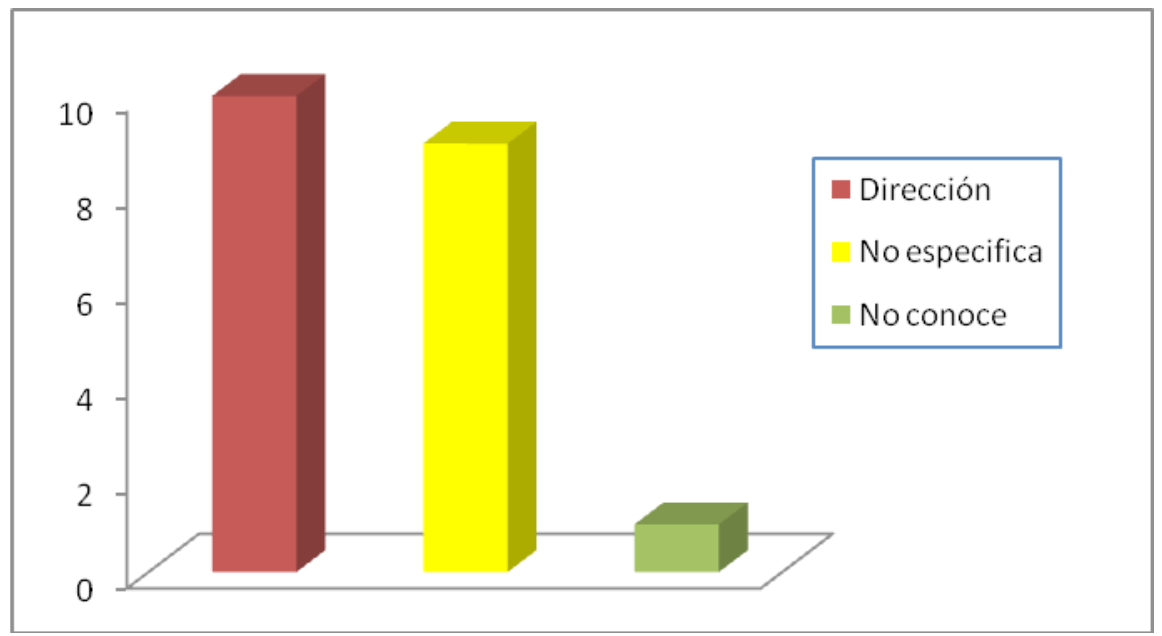

Fuente: Cuestionario aplicado a docentes, 2011.

Consultados los estudiantes acerca del lugar que ocupa la extensión universitaria en el organigrama de las facultades de la UNA, donde asisten, respondieron conforme a los resultados que se presentan en el siguiente gráfico. 
 \\ Gráfico 2 - Órganos de gestión de la Extensión Universitaria según estudiantes}

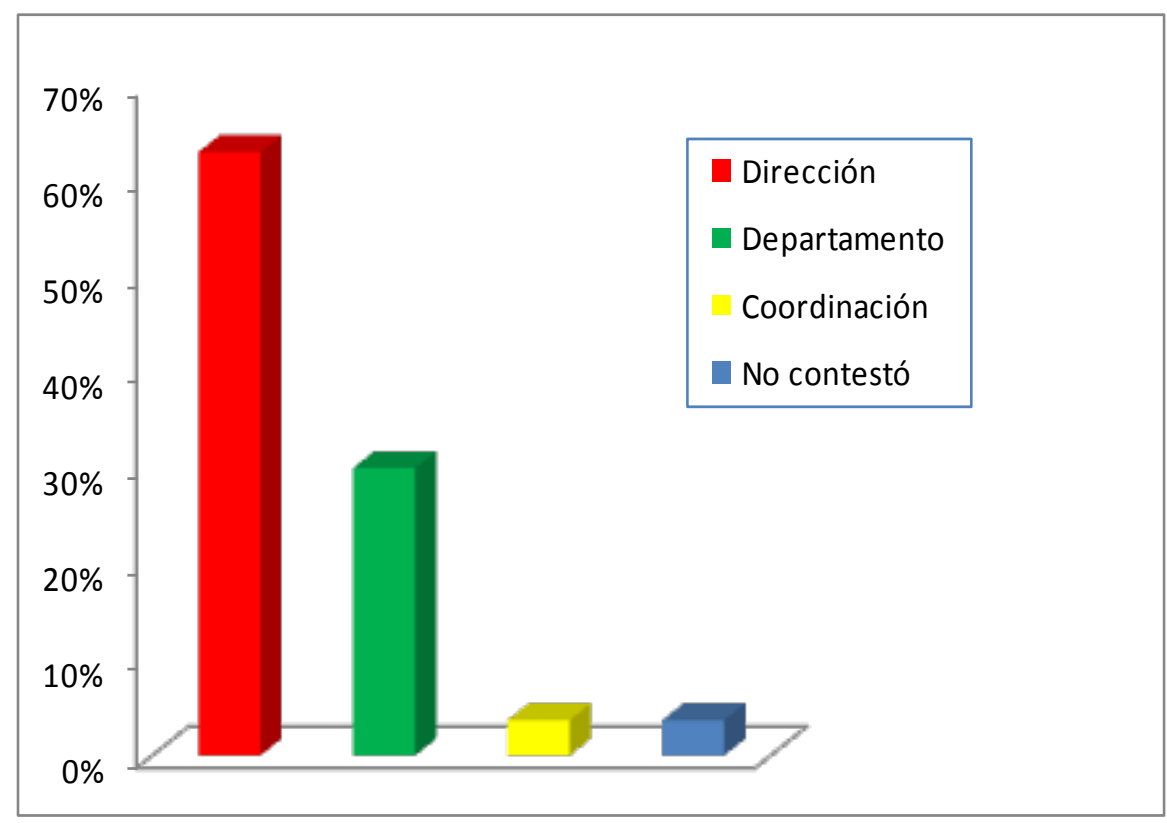

Fuente: Cuestionario aplicado a alumnos, 2011.

\section{VARIABLE 2: GESTIÓN}

En cuanto a la gestión de la extensión en las unidades académicas de la UNA, los resultados obtenidos con la aplicación de los instrumentos a los actores, se detallan a continuación teniendo en cuenta los indicadores establecidos.

\section{Planificación}

Respecto a la planificación de las actividades de extensión, se destaca en los testimonios de los entrevistados que en todas las unidades académicas se diseñan proyectos a través de los cuales se concretan las acciones.

Así se manifestaron los directivos:

“...se planifican como proyectos específicos, proyecto de cátedra intra y extramuros, actividad extracurricular ocasional como cursos y congresos y como parte de la planificación institucional". 
“...se planifican las actividades de extensión como cursos extracurriculares, servicio a la comunidad (asistencia social), como actividades culturales, deportivas, como publicaciones y transmisiones electrónicas, como congresos, simposios, foros, como exposiciones, talleres, trabajos de campo, como promoción de carreras".

“...se realizan como un programa, como proyectos específicos; del $P O A$ se desprenden los proyectos y como proyecto de cátedra. Todas las actividades que se realizan como extensión son de voluntariado; los programas: PASLI que significa pasantías libres de extensión y PASCA, que significa pasantías de extensión de cátedras. Contamos con un formulario de proyectos y pueden surgir desde el Centro de Estudiantes, de una cátedra, de un docente, de estudiantes, de la propia Dirección de Extensión, o un pedido de afuera. Se deben crear tres actividades por semestre como mínimo y los estudiantes eligen un tutor para la realización del proyecto".

Los docentes coincidieron con estas afirmaciones y agregaron que:

“...las actividades son programadas con un año de anticipación en formato de proyecto, que debe ser analizado y aprobado por el Consejo Directivo de la Facultad" (docente de la FOUNA).

“... se presentan como proyecto o a través de una solicitud explícita de la actividad por parte de los participantes o beneficiarios". (Docente de Ciencias Agrarias).

“...se presentan a través de pedidos de empresas, ideas propias de encargados de Laboratorio o encargado de Cátedra, director de Carrera o profesor orientador" (docente de la Facultad Politécnica).

“...se realizan a través de proyectos presentados por las coordinaciones de carreras, previamente aprobados por el Consejo Directivo"; “... los proyectos pueden ser presentados por estudiantes, docentes y/o funcionarios, pero siempre con un docente como tutor". (Docentes de la FACEN)

Se presentan a continuación los resultados obtenidos con los estudiantes con relación a la planificación. 


\section{Gráfico 3 - Planificación de la extensión universitaria según estudiantes}

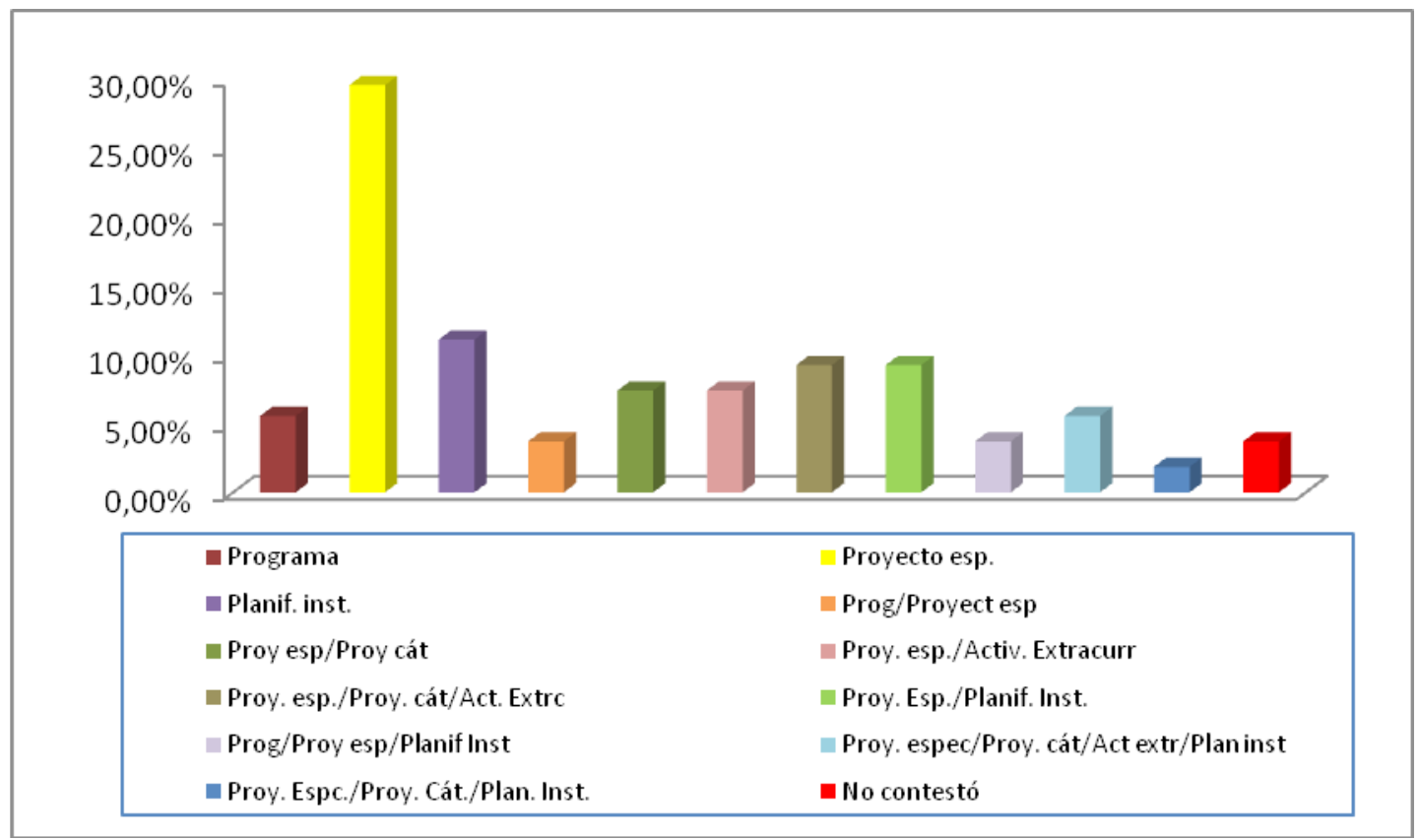

Fuente: Cuestionario aplicado a estudiantes, 2011.

\section{Participantes en la Planificación y eJeCuCión}

Respecto a quiénes participan en la planificación y ejecución de las actividades de extensión, se destaca en los testimonios de los entrevistados que en todas las unidades académicas los primeros responsables de planificar los proyectos de extensión son los integrantes de los departamentos de extensión. Con relación a la ejecución de los proyectos, también coinciden en que son los estudiantes y docentes los protagonistas principales. Así se manifestaron los directivos:

“...es la misma facultad el que planifica y participan en la misma los integrantes de los departamentos de extensión, los coordinadores académicos, los catedráticos de la universidad y los estudiantes. Los ejecutores son los docentes, los estudiantes y los docentes investigadores".

“...la planificación se realiza por carreras y por cursos, participando en la misma los estudiantes, quienes eligen, formulan y ejecutan sus proyectos; los directivos solamente asesoran". 
“...es la misma facultad la que planifica, con la participación de los integrantes del Departamento de Extensión y los estudiantes que participan a través del Centro de Estudiantes y otros ya que pueden surgir los proyectos de cualquier estamento de la facultad, en coordinación con el Departamento de Extensión. En cuanto a la ejecución, son los estudiantes, técnicos de la facultad, docentes de cada departamento quienes ejecutan las acciones".

“...son las filiales las que planifican; cada filial envía su plan y cada departamento envía a sus respectivas carreras; participan directamente de la planificación los catedráticos y de la ejecución los estudiantes y docentes" (D4).

Los docentes también respondieron a este planteamiento diciendo:

"...sí, participo en la planificación y ejecuto las actividades"; "no participo en la planificación pero sí en la ejecución de las actividades" (Docentes de la FOUNA).

“...sí,participo en la planificación yejecución ayudando a los estudiantes, realizando asistencia técnica”. (Docente de Ciencias Agrarias.

“...sí,participo en la planificación cuando voy a ser tutora”; "sí, planifico cuando yo presento el proyecto"; "sí, participo en la planificación y ejecución cuando el proyecto surge en mi cátedra". (Docentes de la FACEN)

El siguiente gráfico es una muestra de los resultados obtenidos con relación a la participación en la planificación y ejecución de los estudiantes en las actividades de extensión según opinaron los mismos. 
Gráfico 4 - Participación en las actividades de extensión, según estudiantes de las facultades: Politécnica, FOUNA, FCA, FCV, FACEN.

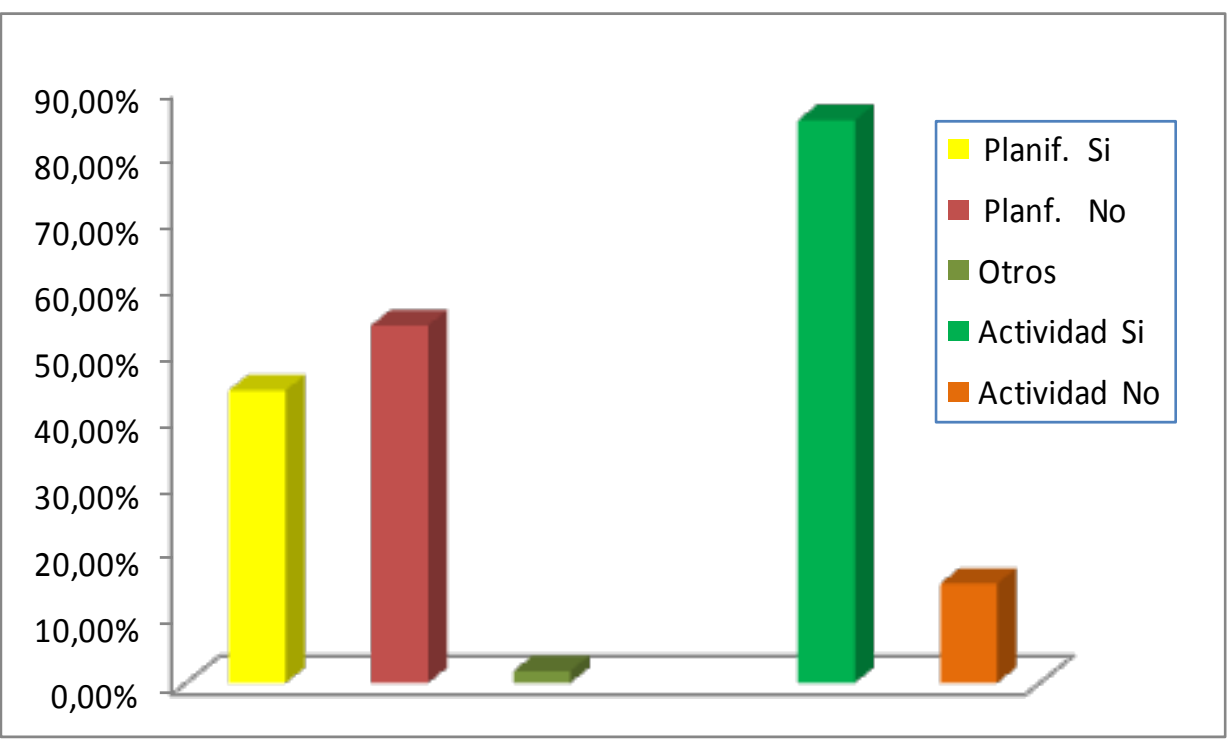

Fuente: Cuestionario aplicado a estudiantes, 2011.

\section{Seguimiento al deSARrollo de las aCtividades de EXTENSIÓN}

Con relación al plan de seguimiento de las actividades de extensión se destaca en los testimonios de los entrevistados, que en todas las unidades académicas existe un plan o mecanismo de seguimiento de las actividades que se realiza a los proyectos de extensión.Los directivos fueron los únicos consultados en este punto. Así se manifestaron los mismos:

“...contamos con un plan de seguimiento de las actividades y son los docentes investigadores quienes se encargan de ello. Tenemos resultados parciales de las acciones realizadas y para medir el impacto de las acciones de extensión, se trabaja con investigación”.

“...el plan de seguimiento se implementó desde el 2011, pidiendo informes a los tutores y estudiantes. No teníamos nada registrado desde el 2008, pero de este seguimiento se encarga una trabajadora social que está dentro de la coordinación. 
“...sí tenemos un plan de seguimiento de las actividades; cada departamento tiene su sistema de dar seguimiento y envían informes trimestrales; se encarga cada coordinador dentro de sus respectivas filiales y departamentos, orientado y supervisado por la casa matriz (de la facultad), luego se pasa a la Dirección General de Extensión de la UNA.

“...sí existe un plan de seguimiento y se encarga del mismo el coordinador y sus brazos, el profesor orientador que presenta su informe de cumplimiento de metas".

\section{Evaluación (RESUltados - IMPACTO)}

En cuanto a la evaluación de las actividades de extensión, se destaca en los testimonios de los entrevistados que en la mayoría de las unidades académicas aún no se realiza evaluación de impacto, pero citaron que existen resultados concretos. Así se manifestaron los directivos:

“...este año estamos cumpliendo 3 años de atención en 8 localidades, lo cual permitirá medir el impacto, para el efecto se hacen encuestas, se prepara a los maestros, padres de familia, se documentan todas las acciones".

“...la evaluación de impacto se visualiza porque hay comunidades que vienen al local de la Facultad y producen, y un 50\% dejan a la facultad y $50 \%$ llevan (producción de hortalizas y plantas medicinales).

“...no existe una evaluación de impacto, pero que se puede citar un resultado interesante que puede ser considerado como un impacto: La Accesibilidad Arquitectónica. La facultad formuló la norma, fue corredactora, en los edificios públicos de Asunción".

“...no tenemos una evaluación de impacto, pero la percepción es que hay una alta satisfacción de los beneficiarios cuando se llega a la meta; se nota satisfacción a través de pedidos y notas de reconocimientos; se puede citar también que las acciones de extensión permiten la inserción laboral y que da pie a convenios de cooperación entre la facultad y las empresas (ANDE, BANCO CENTRAL, LASCA, PARESA)".

También los docentes, con relación a la evaluación de impacto de las acciones de extensión, manifestaron en coincidencia con los directivos, diciendo cuanto sigue: 
“...desde el 2010 se aprobó el Manual de Gestión de la Extensión que prevé la medición de impacto"; "hay un impacto social, como la enseñanza y el aprendizaje, la difusión de la salud bucal específicamente”. (Docentes de la FOUNA)

“...no se lleva a cabo una evaluación sistemática de los resultados e impactos de las actividades, pero la percepción que tiene la comunidad es buena". (Docente de Ciencias Agrarias)

“...los resultados se miden a través de informes cualitativos y cuantitativos que se remitian en forma trimestral y hace un tiempo en forma mensual"; "puede visualizarse en el uso que se le da al producto, por ejemplo las Bibliotecas organizadas técnicamente"; "los resultados se ven con la incorporación de los estudiantes a las empresas". (Docentes de la Politécnica)

Respecto del impacto que tiene la extensión universitaria, los resultados obtenidos con los estudiantes se presentan en el siguiente gráfico.

\section{Gráfico 5 - Resultados que produce la extensión según estudiantes}

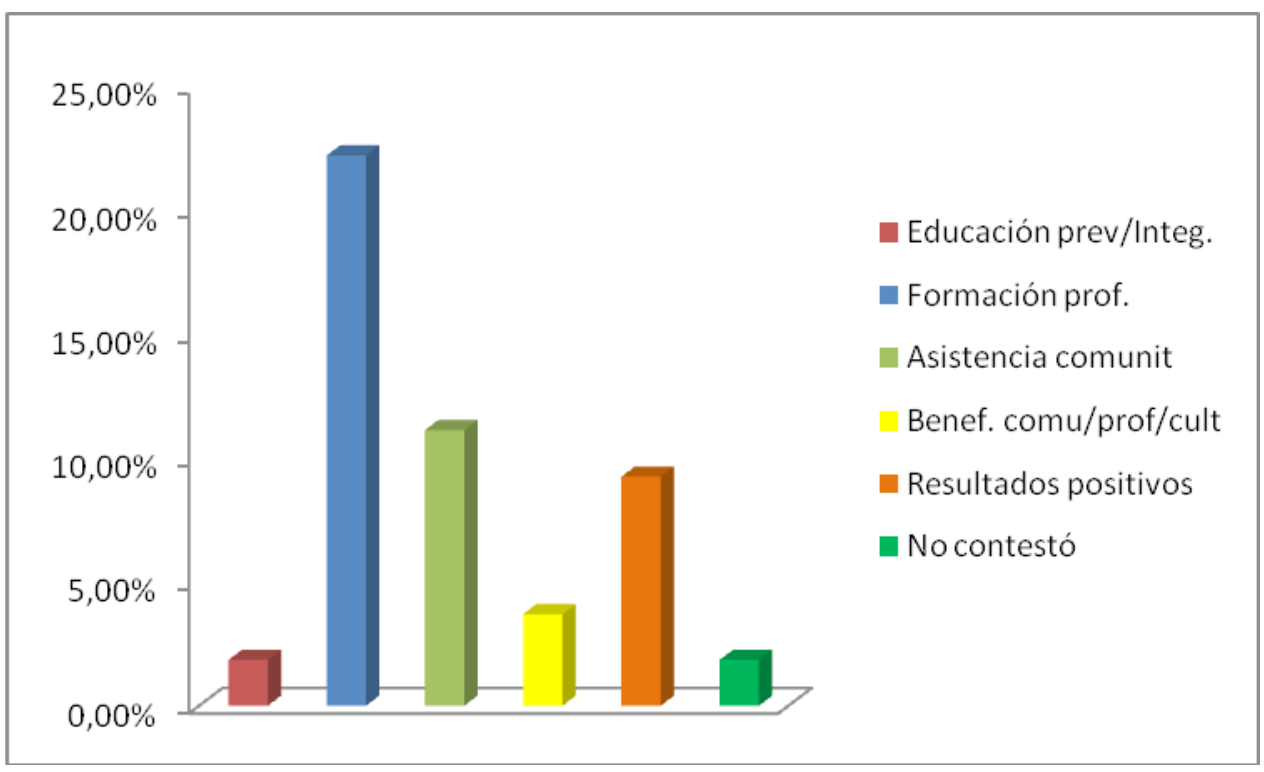

Fuente: Cuestionario aplicado a estudiantes, 2011. 


\section{NoRMativas QUE REgUlan LAS ACCIONES}

En cuanto a las normativas que regulan las acciones de extensión universitaria, los directivos de todas las unidades académicas en estudio coincidieron en señalar el Estatuto de la UNA y el Reglamento General de Extensión Universitaria. Algunos directivos agregaron cuanto sigue: “...el Reglamento interno o específico de extensión universitaria de la FOUNA aprobado por el C.S.U., la planificación institucional anual y el Manual de Operaciones aprobado por el Consejo Directivo de la FOUNA".

“...no tenemos aún reglamento interno de extensión de la facultad”.

Los docentes coincidieron en señalar los documentos que citaron los directivos, pero hicieron referencias también a otros más específicos. Se transcribe lo señalado:

“...las fichas clínicas en caso de actividades asistenciales y planillas con cargas horarias de Extensión”. (Docente de FOUNA)

“... Sistema informático de extensión, registros y planillas”. (Docentes de la FACEN)

\section{DOCUMENTOS DE REGISTRO DE LAS ACTIVIDADES}

Los estudiantes fueron consultados sobre los documentos donde se registran las acciones de extensión y se presentan en el siguiente gráfico los resultados.

Gráfico 6 - Registro de las acciones de extensión, según estudiantes.

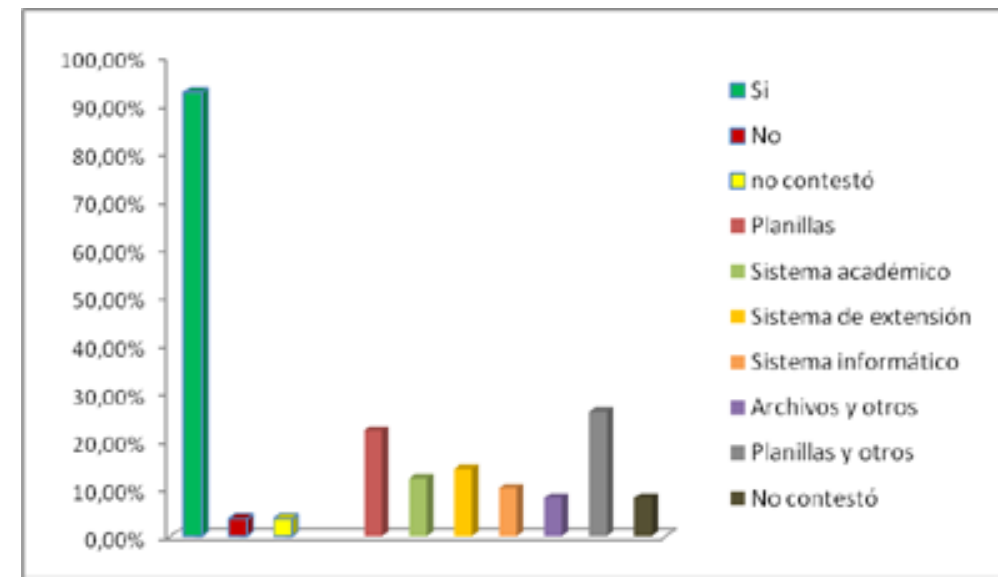

Fuente: Cuestionario aplicado a estudiantes, 2011. 


\section{FinANCIAMIENTO Y RECURSOS DISPONIBLES}

Con relación al financiamiento y los recursos que dispone cada unidad académica para las acciones de extensión, los directivos manifestaron diferentes fuentes y recursos. He aquí algunos testimonios:

“...se realiza con fuente 30, que son los fondos institucionales; con donaciones realizadas por los docentes investigadores cuyos proyectos son financiados por el Rectorado de la UNA. Con la presentación de proyectos de investigación, se logran, con fondos del Rectorado comprar los equipos; que la facultad también dona".

“...los estudiantes hacen su autofinanciación y además a través de convenios y apoyos externos, como la Corte Suprema de Justicia, la Fundación Saraki y la organización Un techo para mi país”.

“...se realiza con aportes de otras instituciones o convenios y otras modalidades como caja chica, autofinanciamiento, a través de actividades que realizan los departamentos como capacitaciones, congresos a través de sponsor".

“...se financia con el presupuesto de la facultad, con aportes de otras instituciones o convenios citando como ejemplo al Rotary Club y como forma de apoyo las instituciones que colaboran con combustible para la movilidad, con insumos tales como semillas, equipos, herramientas".

Una de las docentes investigadoras de la Dirección de Extensión de la FOUNA manifestó lo siguiente:

"Reciclamos los equipos viejos (luz halógena, torno, otros) y estamos viendo la posibilidad de hacer un sillón plegable".

Con relación a la gestión de la extensión, en el análisis de documentos realizados, se obtuvieron los resultados que se presentan a continuación:

Tanto el Reglamento General de Extensión de la UNA como los reglamentos internos de extensión de cada facultad presentan en sus capítulos las atribuciones y deberes de los órganos de extensión, las orientaciones para la planificación de la extensión, las actividades de extensión a ser desarrolladas y dónde podrán ser ejecutadas. También los aspectos básicos que se considerarán en el momento de elaborar los proyectos.

También se presenta la participación de los estudiantes, la participación de los docentes y la forma de registrar la participación. Con relación a la carga horaria de extensión que deben cumplir los estudiantes, algunas 
facultades, como Odontología, hicieron ajustes aumentando las horas de extensión.

\section{VARIABLE 3: PROPÓSITOS}

Con relación a los propósitos que orientan las acciones de extensión de las facultades en estudio, se presentan a continuación los testimonios de directivos de las unidades académicas en estudio, quienes en varios casos coincidieron en señalar como principales propósitos el servicio a la sociedad y el fortalecimiento del perfil profesional en los estudiantes.

"Uno de los principales propósitos es prestar ayuda a poblaciones necesitadas, a las más vulnerables en salud bucal; también el fortalecimiento del perfil profesional de los futuros profesionales de modo a adaptarse a la realidad nacional".

"El propósito fundamental es devolver a la comunidad lo que están recibiendo, en forma de conocimientos, servicios, investigaciones".

"El propósito es prestar ayuda a poblaciones necesitadas; también brindar servicios de formación continua a diferentes sectores como estudiantes principiantes y además fortalecer el perfil profesional de los futuros profesionales".

"El propósito más importante es el de fortalecer el perfil profesional de los futuros profesionales, también el de prestar ayuda a poblaciones necesitadas; la retroalimentación es la función más importante de la extensión”.

Algunos docentes también coincidieron con lo manifestado por los directivos:

"El propósito es la formación sociohumanista del profesional odontólogo"; "Es la vinculación de los participantes con la sociedad a fin de formar el sentido de responsabilidad social en el estudiante". (Docentes de la FOUNA)

"El propósito es fortalecer la relación universidad-comunidad-empresa". (Docente de la Politécnica)

"El propósito es contribuir a la resolución de necesidades y problemas específicos de la sociedad además de fomentar en docentes y estudiantes la vocación de servicio". (Docente de la FACEN) 
Siguiendo con los propósitos que orientan las acciones de extensión de las facultades en estudio, se presentan a continuación en el gráfico los resultados obtenidos en el cuestionario aplicado a los estudiantes.

\section{Gráfico 7 - Propósitos de la extensión, según estudiantes}

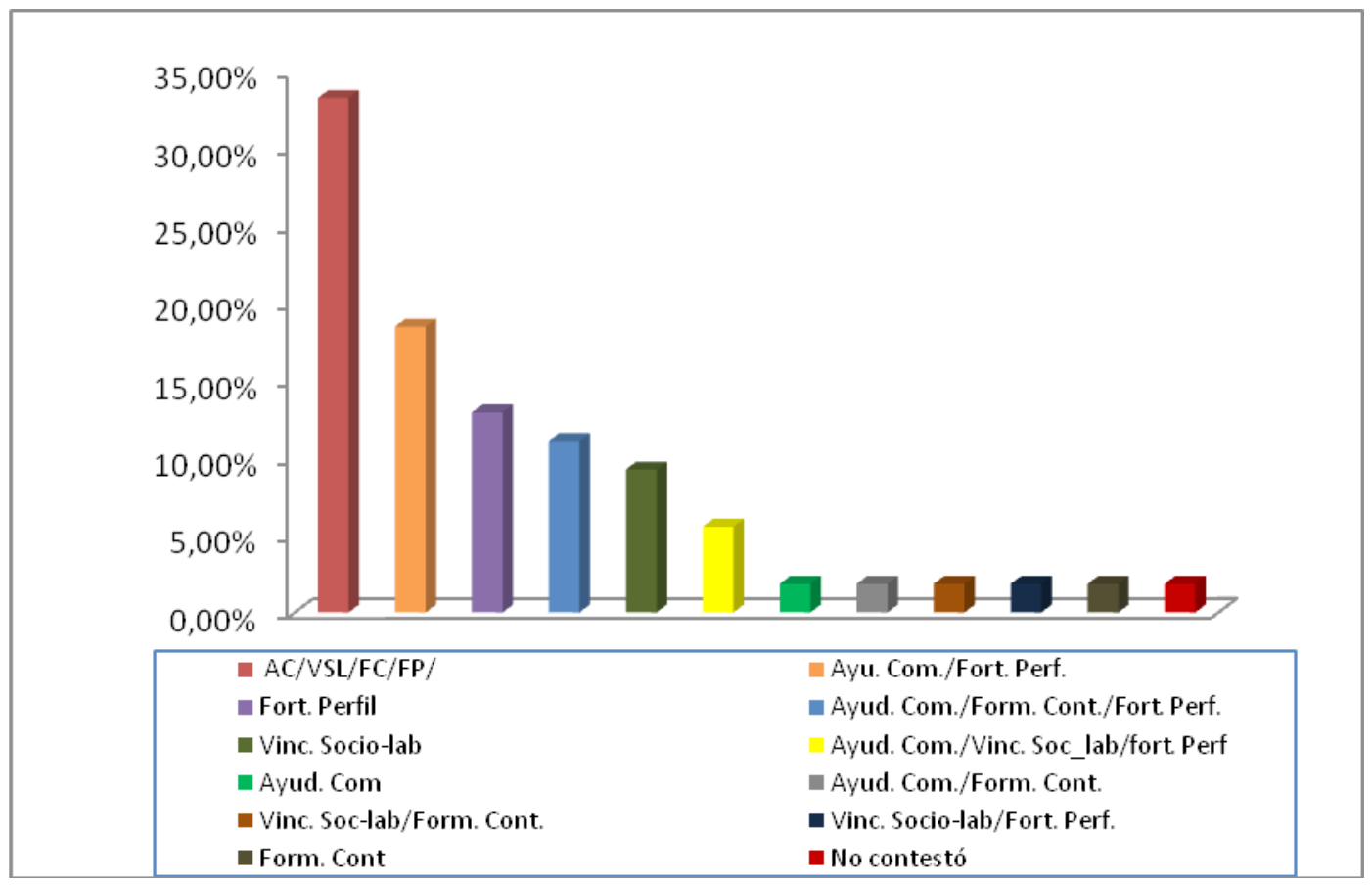

Fuente: Cuestionario aplicado a estudiantes, 2011

A través del análisis de los documentos que regulan las acciones de extensión universitaria:

Se ha logrado verificar que el Estatuto de la UNA, en su Art. 107, presenta los propósitos, haciendo referencias de cómo se orientarán las acciones de extensión. En el Reglamento General de Extensión de la UNA, no se citan en forma explícita los objetivos o propósitos de la extensión. Sin embargo, el Reglamento Interno de Extensión de cada facultad en estudio presenta los objetivos de la extensión universitaria. 


\section{VARIABLE4:ACCIONESDESARROLLADASCOMOEXTENSIÓN}

Los datos recogidos respecto de esta variable se presentan en gráficos y se han obtenido de las entrevistas realizadas a los directivos, el cuestionario aplicado a los docentes y estudiantes, así como del análisis de los documentos.

Es importante destacar que en lasentrevistas realizadas en los departamentos de extensión universitaria de las facultades en estudio, algunos directivos detallaron las acciones realizadas con mucho entusiasmo. Tal es el caso de un directivo cuyas expresiones se presentan a continuación:

"Iniciamos la extensión empíricamente, con eliminación de foco séptico, pero lo que actualmente hacemos es educación. La extensión es muy sacrificada, pero la satisfacción es grande cuando se presta servicio; igracias, doctora! son las exclamaciones que se reciben".

Se reproducen también las expresiones de otro directivo de una facultad:

"Sobresalen entre las acciones de extensión el Festival del Agro que se realiza cada año y los días de campo donde participan los productores de la zona, por sobre todo los familiares de los estudiantes".

En el siguiente gráfico se presentan los resultados obtenidos en las entrevistas con los docentes, quienes especificaron con nombres las acciones realizadas en extensión en sus facultades.

Gráfico 8 -Acciones realizadas en extensión universitaria. Según los docentes.

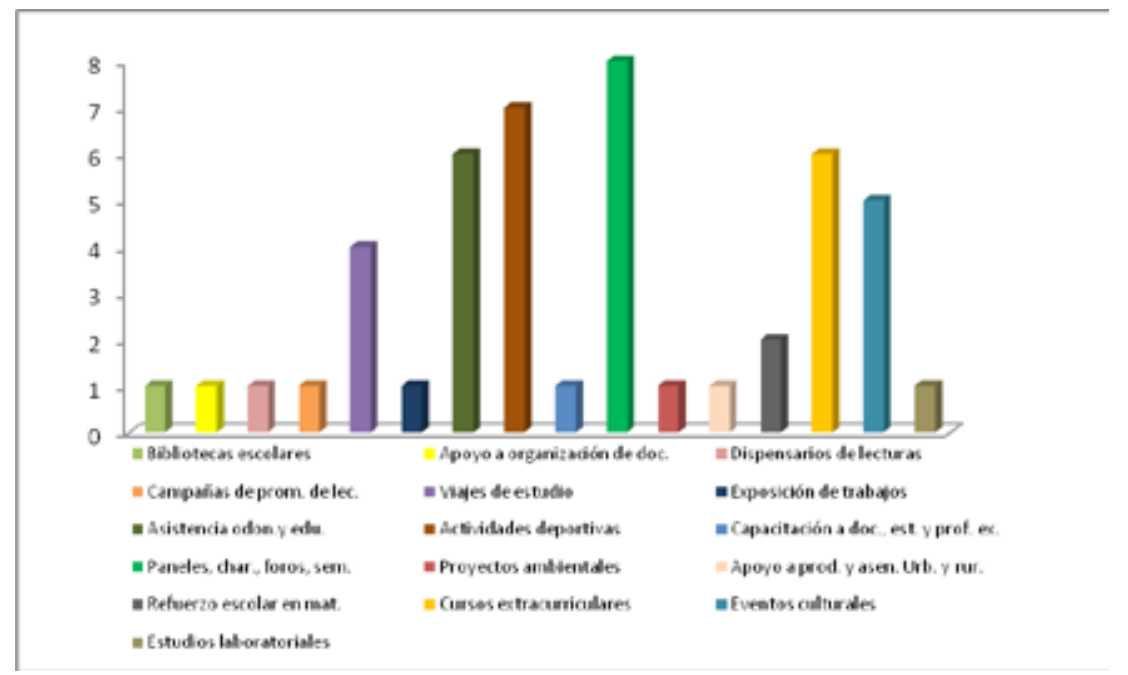

Fuente: Cuestionario aplicado a los docentes, 2011 
Con relación a la incidencia que tienen o puedan tener estas acciones en los planes de desarrollo del país expresaron, entre otros:

"Se presta servicio donde el Estado a veces no puede llegar"; "Contribuye a mejorar la calidad de vida del ciudadano".

Entre las líneas de mejora citaron la necesidad de adquirir más equipamientos para agilizar y facilitar los trabajos realizados durante las atenciones y programar más actividades culturales.

Sobresalen en consultas realizadas tanto a directivos como a los docentes las acciones correspondientes a programas de asistencia social a las comunidades carenciadas.

Los resultados de los datos obtenidos a través de las encuestas aplicadas a los estudiantes con relación a las acciones de extensión universitaria son presentados a través del gráfico siguiente.

\section{Gráfico 9 - Acciones de extensión, según estudiantes.}

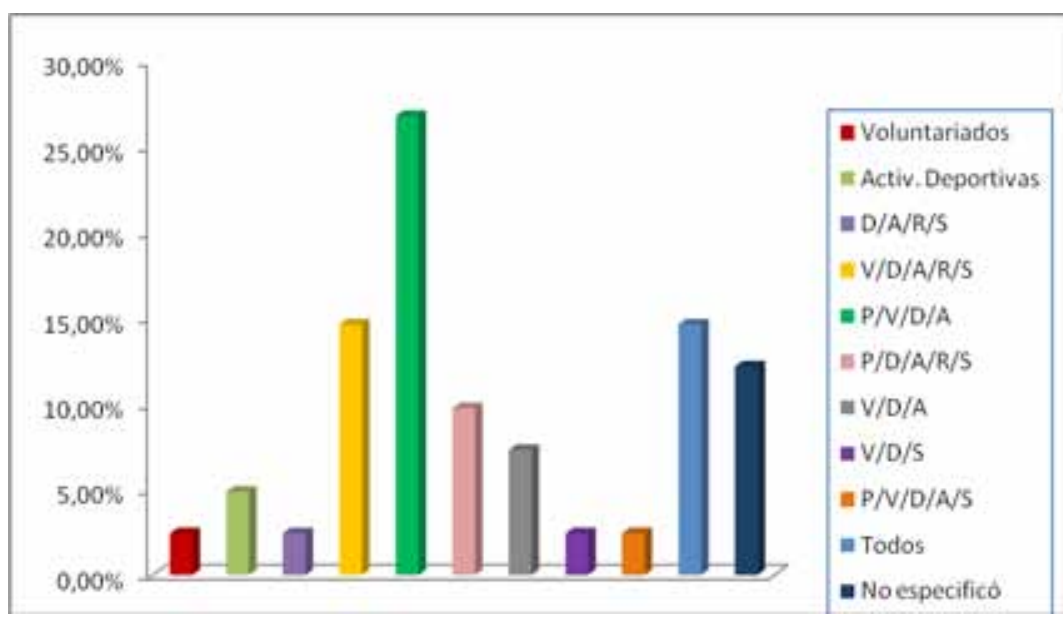

Fuente: Cuestionario aplicado a estudiantes, 2011.

Los estudiantes optaron por varias respuestas, presentadas como opciones por lo cual las acciones más citadas por los estudiantes fueron las correspondientes a: pasantías, voluntariados, actividades deportivas y actividades artísticas. También se reiteran entre las respuestas las actividades sociales. En cuanto a los voluntariados algunos estudiantes especificaron los servicios a la comunidad. 


\section{DISCUSIÓN}

Se destaca que para analizar la organización y el funcionamiento de la extensión universitaria se ha recurrido a sus fuentes principales: sus directivos y los documentos oficiales que la respaldan. La posibilidad que se tuvo de acceder a los responsables de los órganos de gestión de la extensión en las siete facultades de la UNA, abrió el camino para poder realizar este estudio. De igual modo, el acceso a los documentos también dio apertura para realizar, a través del análisis, una revisión teórica de la organización y funcionamiento de la extensión.

En cuanto a los docentes y estudiantes como sujetos participantes, por un lado dio amplitud a la recolección de datos; sin embargo, la falta de acceso directo a las aulas, por no tratarse de la función de la docencia, limitó la posibilidad de aumentar las muestras.

Se considera al llegar a esta instancia que los resultados obtenidos son válidos, ya que los responsables directos de la gestión han dado sus informes a través de entrevistas directas, y con los documentos que avalan dichas informaciones.

En la búsqueda del soporte teórico para este trabajo, se han encontrado algunas experiencias de organización y funcionamiento que presentan características muy similares a las analizadas en las realidades de las facultades de la UNA en estudio. Podemos citar el trabajo de investigación acerca de la extensión de las universidades privadas, realizada por el CONEC en nuestro país; así también la extensión en la Universidad de la República y de otras de Latinoamérica, en cuanto a sus conceptualizaciones, funciones, gestiones, propósitos y acciones.

Este trabajo, que se contextualiza en el marco de un proceso de evaluación de los criterios de calidad para la acreditación de las carreras y por ende de las facultades, refuerza la necesidad de seguir analizando el grado de importancia que se le da a la extensión universitaria dentro del proyecto académico de las universidades, y diseñar estrategias que permitan la integración y coordinación de las actividades de docencia, investigación y extensión. 


\section{$=$

\section{CONCLUSIONES}

A continuación se presentan las conclusiones respecto a cada objetivo específico planteado.

ESTRUCTURA ORGANIZACIONAL DE LA EXTENSIÓN UNIVERSITARIA EN LAS FACULTADES DE LA UNA

En general se puede afirmar que hay una estructura organizacional de la extensión universitaria en cada facultad, visualizada en órganos responsables de su organización y gestión, con tres denominaciones distintas, predominando la dirección que da oportunidad en algunas facultades a distribuir las responsabilidades en coordinaciones de extensión por carreras.

Esta estructura, así como las instancias específicas son conocidas por los actores educativos, aunque algunos estudiantes y docentes no las puedan precisar por sus nombres, lo que puede deberse a una comunicación y difusión aún insuficiente de la extensión universitaria al interior de toda la institución.

Esta estructura organizacional de la extensión en cada facultad, responde a lo establecido en el Reglamento General de la Extensión Universitaria de la UNA que determina en forma clara y precisa que cada facultad incluirá dentro de su estructura orgánica el funcionamiento de un departamento de extensión, con el equipamiento físico, los recursos humanos y las asignaciones presupuestarias, que posibiliten el cumplimiento de sus planes operativos.

El proceso de instalación de los órganos de gestión de la extensión universitaria dentro de la estructura organizacional de las facultades de la UNA y sus reglamentaciones propias, es relativamente nuevo aunque las acciones de extensión, en algunas facultades, se dieron desde su creación.

En los últimos años en nuestro país, con la necesidad de la acreditación de las carreras, las facultades en general están pasando por un proceso que exige ajustar las diversas dimensiones de la organización institucional, a los estándares de calidad que presentan las agencias regionales y nacionales que se encargan de la evaluación, lo que se puede vincular con el fortalecimiento de la estructura organizativa de la extensión visualizada en esta investigación.

Es importante considerar que la existencia de una estructura organizacional definida, ayuda a la funcionalidad de la gestión y se constituye en un 
medio fundamental que facilita el logro de los objetivos. En este estudio, se hizo referencia a la extensión universitaria de la UNA de las siete unidades académicas investigadas y se pudo comprobar que poseen un lugar dentro del organigrama.

\section{Características de la gestión de la eXtensión universitaria en laS FACULTADES DE LA UNA}

Se mencionaba más arriba que la estructura organizacional favorece a la buena gestión dentro de una institución. En el caso de las direcciones, departamentos y coordinaciones de extensión universitaria de las facultades en estudio, se puede concluir que existe una gestión que tiende a ser participativa, ya que en la planificación y la ejecución de las acciones de extensión universitaria participan, en la mayoría de los casos, los diversos actores educativos, pero aún con débil proceso de seguimiento y ausencia o poca sistematización del impacto de las acciones.

Otra característica de la gestión se refiere a la existencia de normativas además que le proporciona un soporte legal y normativo que incorporan sus políticas y posibilitan la concreción de las mismas. Asimismo, se destaca que las actividades de extensión se registran en diversos documentos e incluso forman parte de publicaciones de las instituciones, lo que facilita la difusión de las experiencias.

En lo que se refiere a la financiación, se percibe un esfuerzo por parte de las facultades para la obtención de los recursos necesarios; no obstante, se evidencia también la falta de un presupuesto destinado a la extensión se otorga al eje docencia o formación profesional de las instituciones. Esto constituye un indicador de que la extensión aún no se ha equiparado en importancia con la función de formación o docencia.

La gestión de la extensión en las facultades en estudio de la UNA presenta características comunes con la de diversas universidades latinoamericanas expuestas en este trabajo en cuanto a: el esfuerzo por lograr la participación en las diferentes etapas, en cuanto al ámbito de concreción dentro y fuera de la universidad y en cuanto a los propósitos de la extensión.

\section{Propósitos de la eXtensión en las facultades de la UNA}

Se concluye que diversos son los propósitos que se presentan, según lo expresado en los documentos y manifestaciones de los docentes, los directivos y los estudiantes. 
Se cumplen estos propósitos en mayor o menor frecuencia con base también en la naturaleza de las carreras. Sin embargo, el propósito identificado por medio de las acciones es el de prestar servicios o apoyar a la comunidad, cumpliendo de esta manera lo que se consigna en uno de los puntos del Estatuto de la UNA.

Cabe recordar que un estudio realizado a universidades privadas del Paraguay, a través de un programa de investigación impulsado por el Consejo Nacional de Educación y Cultura entre mayo y agosto del año 2000, se obtuvo como uno de los resultados que, entre otros propósitos, un grupo vincula la extensión al mero asistencialismo, describiendo en este punto las actividades de este tipo orientadas a personas de escasos recursos. A través de este estudio se puede afirmar que la idea de servicio en las facultades en estudio de la UNA se clarifica, según se expresa en su Estatuto: "La extensión universitaria se orientará a: extender a la sociedad el quehacer institucional de la universidad y los resultados del trabajo académico, favoreciendo acciones encaminadas a prestar servicios o apoyar a la comunidad" (Art. 107).

Un claro ejemplo de haber pasado del asistencialismo al servicio educativo lo constituye la FOUNA, que lo testimonia la responsable de Extensión, habiendo expresado en la entrevista que "hoy hacen educación".

Clasificación de las acciones de eXtensión universitaria QUe DESARROLLAN LAS FACULTADES DE LA UNA

Las acciones que se desarrollan en las facultades de la UNA, se enmarcan dentro de lo establecido en el Estatuto, en el Reglamento General de Extensión y en el Reglamento Interno de cada facultad.

Se puede concluir que las acciones se agrupan de acuerdo a los propósitos que se plantean de acuerdo a las perspectivas o enfoques de la extensión. Ellas son:

- Actividades formativas dirigidas a la comunidad interna y externa.

- Servicios comunitarios de asistencia social.

- Actividades culturales, deportivas y recreativas.

- Asesorías y servicios profesionales.

- Pasantías, viajes de estudio y seguimiento a egresados. 
Se concluye que esta clasificación se ha dado considerando el enfoque de comunicación mutua entre la sociedad y la universidad, con la idea de servicio social a la comunidad y de extensión y difusión cultural.

\section{DOCUMENTOS QUE SISTEMATIZAN LAS ACCIONES DE EXTENSIÓN UNIVERSITARIA EN LAS FACULTADES DE LA UNA}

Se concluye que la existencia de documentos que dan un soporte jurídico fundamental y que registran adecuadamente las acciones de extensión universitaria en las unidades académicas en estudio, son evidencias de que existe una gestión y organización de la extensión en las facultades de la UNA reglamentada y sistematizada. Así también, que las revistas de extensión favorecen la difusión de las acciones realizadas.

Además se menciona que con la adecuada documentación para el registro de las actividades que realizan los estudiantes, se considera a la extensión como una exigencia académica que debe ser cumplida, así como la docencia y la investigación.

\section{Desafíos Pendientes}

En este apartado final del estudio se presentan algunas ideas a modo de desafíos, con relación a esta tercera misión de la universidad:

1. Conocer el grado de compromiso académico y social que les genera a los estudiantes y docentes universitarios la participación en las acciones de extensión.

2. Afianzar la comunicación y difusión de la extensión al interior de las universidades.

3. Medir con mayor sistematización el impacto de las acciones que se realizan, tanto en la comunidad académica como en el contexto social donde se desarrollan.

4. Dar sostenibilidad y sustentabilidad a los proyectos de extensión universitaria, conforme a las necesidades que existen en la sociedad y a las políticas públicas contempladas en los planes de desarrollo del país. 


\section{UNIBE

\section{BIBLIOGRAFÍA}

AGUILERA MÉNDEZ, Raúl. (2010). Catálogo de Normas Legales vinculadas a la Educación Superior. Ediciones y Arte. Asunción, Paraguay.

ANEAES. (2007). Modelo Nacional de Acreditación de la Educación Superior. Parte 2: Guía para la Autoevaluación. MEC. ANEAES. BID. Asunción. Paraguay.

BORDA FERRER, Mariano. (2004). La Universidad amordazada. Intervención de la Universidad Nacional y Movimiento Estudiantil de 1954. La crisis actual de la Universidad. Asunción. Intercontinental Editora.

CANO, Agustín. (2010). Apuntes para la intervención en el panel "La extensión universitaria en el campo profesional del diseño". Extraído el día 5 de enero de 2012, de:http://universidad.academia.edu/ Agust\%C3\%ADnCano/Talks/60423/La_extension_universitaria_en_el_ campo_profesional_del_diseno.

CARLEVARO, Pablo V. (2009). Universidad y sociedad: proyección y vínculos. Extraído el día 5 de enero de 2012, de:http://redalyc.uaemex. $\mathrm{mx} / \mathrm{src} /$ inicio/ArtPdfRed.jsp?iCve $=34011860009$

CONEC. (2002). Estrategias de transformación de la Educación Superior. Asunción, Paraguay.

CONEC. (s/f). Nueva Ley de Educación Superior: Evaluación de Propuestas y sugerencias de principales criterios y lineamientos a incorporar.

Congreso de la Nación. Diagnóstico y propuesta para la Educación Superior en el Paraguay. Informe preliminar (2005). Comisión Bicameral para el estudio de la Reforma de la Educación Superior. Asunción, Paraguay. Comisión Nacional para la Reforma de la Educación.

Conferencia Mundial sobre la Educación Superior. UNESCO. París 2009. Extraído el 5 de mayo de 2011, de: http://www.unesco.org/ education/WCHE 2009/comunicado_es.pdf

Del Huerto Marimón, María Elena. (2007). La Extensión Universitaria como vía para fortalecer los vínculos Universidad - Sociedad desde la promoción de salud. Extraído el día 10 de enero de 2012, de:http:// redalyc.uaemex.mx/src/inicio/ArtPdfRed.jsp?iCve=21433205 
Diccionario de la Real Academia Española. Vigésima Segunda Edición. 2001

Documento de la Conferencia mundial sobre la Educación Superior 2009. Extraído el día 12 de junio de 2011, de:http://www.unc.edu.ar/ seccion/novedades/2009/julio/documento-de-la-conferencia-mundial-deeducacion

ELÍAS, Rodolfo y SERAFINI, Diana (2006). Caracterización del Sector Privado de la Educación Superior Universitaria en Paraguay. Asunción, Paraguay. CONEC.

Estatuto de la UNA. Extraído el 25 de enero de 2012, de:

http://www3.una.py/pdf/estatuto-una-2005.pdf

Estatuto de la UNSL, Universidad Nacional de San Luis. Argentina. Extraído el 20 de abril de 2011, de http:// www.extension.unsl.edu.ar/ quees.htm

Extensión Universitaria, un instrumento de interacción y cambio social Universidad de Chile. Extraído el 20 de abril de 2012 de: http://www. uchile.cl/.../extension- universitaria-un-instrumento-de-interacción.

Facultad de Psicología. Universidad Nacional de Rosario. Extraído el 28 de agosto de 2010, de:http://www.fpsico.unr.edu.ar/

GONZÁLEZ TORRES, Dionisio M. (1984). La Universidad Nacional de Asunción. Una etapa de su desarrollo. Asunción, Paraguay. Editorial Litocolor.

GUTIÉRREZ, Ofelia Ángeles.

"Consideraciones en torno al concepto de extensión de la cultura y los servicios". Extraído el día 5 de enero de 2012, de: http://www.anuies. $\mathrm{mx} /$ servicios/p_anuies/publicaciones/revsup/126/01a.html

HERNÁNDEZ SAMPIERI, R. y otros. (2006). Metodología de la Investigación. México: Mc Graw Hill.

Investigaciones y estudios de la UNA. Volumen 2. (2007). Trabajos de Investigación y Estudios de las Facultades de la UNA: Ciencias Químicas, De la Vida, Agrarias, Médicas, Tecnológicas, Económicas, de la Educación y Sociales. Asunción. Paraguay.

Irundú. (2007). Revista Científica de Educación y Desarrollo Social. Universidad Autónoma de Asunción. Asunción, Paraguay. 
JIMÉNEZ VARELA, Horacio Eduardo. (2008). Imperios, Ideologías y Liberación en la Universidad Paraguaya. Elementos para una nueva entidad. Edit. Marben. Asunción, Paraguay.

La Educación Superior en el Siglo XXI Visión y Acción. Conferencia mundial sobre la Educación Superior. Documento de trabajo. UNESCO. París (1998). Extraído el día 12 de junio de 2011, de: http://www.unesco. org/education/educprog/wche/declaration_spa.htm

LATORRE, Antonio. (2007). La investigación-acción. Conocer y cambiar la práctica educativa. Barcelona, España. Edit. GRAO.

MARTÍN, Julio M. (2004). El Mecanismo de Acreditación Universitaria del Mercosur. UNESCO.

MARTÍN-MORENO CERRILLO, Q. (2006). Organización y Dirección de Centros Educativos Innovadores. El Centro Educativo Versátil. McGraw-Hill. España, 2006.

Paraguay: Universidad 2020. Documento de discusión sobre la Reforma de la Educación Superior (2 006). MEC - CONEC - UNA. Asunción. Paraguay.

Planificación Estratégica de la UNA. IESALC y UNESCO (s/f). Aspectos relevantes de la dinámica de la Universidad Nacional de Asunción. Estudios sobre la Universidad Nacional de Asunción. Estudios de Postgrado en Paraguay.

Portal de la Udelar/Extensión.Extraído el 28 de agosto de 2010, de:http:// www.universidad.edu.uy/renderPage/index/pageld/86\#heading_198

RAMA, Claudio (2006). Tercera Reforma de la Educación Superior en América Latina. Fondo de Cultura Económica. México.

Reforma de la Educación Superior. Proyecto sustitutivo de la Ley $N^{o}$ 2529/04 de Universidades (2009). Comisión Nacional de Reforma de la Educación Superior. Consejo Nacional de Educación y Cultura. Asunción. Paraguay

Reglamento de Extensión de la Facultad de Ciencias Agrarias de la UNA. Extraído el 25 de enero de 2012, de: http://www.agr.una.py/descargas/ extension/Reglamento_12-julio2009.pdf

Reglamento General de Extensión de la Universidad Nacional de Asunción. Extraído el 25 de enero de 2012, de: http://www.pol.una.py/ reglamentos/ReglamExtensionUNA.pdf 
Revista Extensión Universitaria 2007. $N^{o} 2$ Universidad Nacional de Asunción. Dirección General de Extensión Universitaria. Campus de la UNA, San Lorenzo - Paraguay

Revista Extensión Universitaria 2008. $N^{o} 3$ Universidad Nacional de Asunción. Dirección General de Extensión Universitaria. Campus de la UNA, San Lorenzo - Paraguay.

Revista Extensión Universitaria 2009. $N^{\circ} 4$ Universidad Nacional de Asunción. Dirección General de Extensión Universitaria. Campus de la UNA, San Lorenzo - Paraguay.

RIVAROLA, Domingo M. (2004). La Educación Superior Universitaria en Paraguay. $2^{\mathrm{a}}$ Edic. MEC - UNESCO - CONEC - IESALC. $2^{\mathrm{a}}$ Edic. Asunción. Paraguay. Ediciones y Arte SRL

SAUTU, R. y otros. (2005). Manual de Metodología. Buenos Aires: CLACSO.

SARUBBIZALDÍVAR, Vicente (s/f). Un Sistema de Educación Superior para el Paraguay Democrático. Asunción Paraguay.

Secretaría de Extensión y Vinculación. Extraído el 28 de agosto de 2010, de: http://www.uaemex.mx/SEyV/index.html

SERNA ALCÁNTARA, Gonzalo Aquiles. (2007). Misión Social y Modelos de Extensión Universitaria. Extraído el 20 de enero de 2012, de:http://www.rieoei.org/deloslectores/1662Aquiles.pdf

TÜNNERMANN, Carlos. (2000). "El nuevo concepto de la Extensión Universitaria”. Extraído el 20 de enero de 2012, de: http://www.udea. edu.co/portal/page/portal/BibliotecaPortal/InformacionInstitucional/ Autoevaluacion/SistemaUniversitarioExtension/NuevoConceptoExtension Universitaria-CarlosTunnermann.pdf

UH/Dirección de Extensión Universitaria. Extraído el 28 de agosto de 2010, de: http://www.uh.cu/infogral/deu/deu.htm

VEGA MEDEROS, Juan Francisco. (2002). La Extensión Universitaria: Función Integradora del Quehacer Universitario en el presente siglo. Extraído el día 24 de enero de 2012, de: http://redalyc.uaemex.mx/src/ inicio/ArtPdfRed.jsp?iCve $=26812103$

VELILLA LACONICH, Julia. (1990). Historia de la Universidad Nacional de Asunción (1889-1989). UNA. Volumen 1, 2, 3. Asunción. Paraguay. 
VILLAR ANGULO, Luis Miguel y ALEGRE DE LA ROSA, Olga

María. (2004). Manual para la excelencia en la Enseñanza Superior. Mc Graw Hill.

ZABALZA, Miguel A. (2002). La Enseñanza Universitaria.El Escenario y sus protagonistas. Madrid. Narcea S.A. 
